\title{
Dynamics of heterogeneous crosslinking in room temperature vulcanizing poly(dimethyl siloxane) and its dependence on moisture supply
}

Citation for published version (APA):

Arends, T., Huinink, H. P., \& Pel, L. (2019). Dynamics of heterogeneous crosslinking in room temperature vulcanizing poly(dimethyl siloxane) and its dependence on moisture supply. Polymer, 164, 8-16.

https://doi.org/10.1016/j.polymer.2018.12.059

Document license:

TAVERNE

DOI:

10.1016/j.polymer.2018.12.059

Document status and date:

Published: 15/02/2019

Document Version:

Publisher's PDF, also known as Version of Record (includes final page, issue and volume numbers)

Please check the document version of this publication:

- A submitted manuscript is the version of the article upon submission and before peer-review. There can be important differences between the submitted version and the official published version of record. People interested in the research are advised to contact the author for the final version of the publication, or visit the $\mathrm{DOI}$ to the publisher's website.

- The final author version and the galley proof are versions of the publication after peer review.

- The final published version features the final layout of the paper including the volume, issue and page numbers.

Link to publication

\footnotetext{
General rights

- You may freely distribute the URL identifying the publication in the public portal. follow below link for the End User Agreement:

www.tue.nl/taverne

Take down policy

If you believe that this document breaches copyright please contact us at:

openaccess@tue.nl

providing details and we will investigate your claim.
}

Copyright and moral rights for the publications made accessible in the public portal are retained by the authors and/or other copyright owners and it is a condition of accessing publications that users recognise and abide by the legal requirements associated with these rights.

- Users may download and print one copy of any publication from the public portal for the purpose of private study or research.

- You may not further distribute the material or use it for any profit-making activity or commercial gain

If the publication is distributed under the terms of Article $25 \mathrm{fa}$ of the Dutch Copyright Act, indicated by the "Taverne" license above, please 


\title{
Dynamics of heterogeneous crosslinking in room temperature vulcanizing poly(dimethyl siloxane) and its dependence on moisture supply
}

\author{
Thomas Arends, Hendrik P. Huinink, Leo Pel* \\ Department of Applied Physics, Eindhoven University of Technology, P.O. Box 513, 5600 MB, Eindhoven, the Netherlands
}

H I G H L I G H T S

- Transverse magnetization relaxation rate dependent on crosslinking.

- Direct observation of a crosslinking front upon exposure to a moisture source.

- Crosslinking front velocity directly related to moisture supply.

- Reaction-diffusion model with material parameters reproduces front diffusivity.

\section{A R T I C L E I N F O}

\section{Keywords:}

Poly(dimethyl siloxane)

Crosslinking

Nuclear Magnetic Resonance

\begin{abstract}
A B S T R A C T
The influence of moisture supply on the crosslinking rate in room temperature vulcanizing poly(dimethyl siloxane) is investigated using spatially resolved ${ }^{1} \mathrm{H}$ nuclear magnetic resonance relaxometry. Using this technique, we observe heterogeneous crosslinking manifested in a front moving into the material from the exposed surface, which separates the crosslinked and uncrosslinked parts of the material. The presence of a sharp boundary indicates that moisture transport towards the front is the limiting factor in the crosslinking process. As a result, the moisture supply controls the crosslinking front velocity, which we capture in a diffusion-reaction model. Reasonable agreement is found between the front diffusivity retrieved directly from nuclear magnetic resonance experiments and calculated values using independently measured properties of the crosslinked silicone rubber. This result demonstrates the direct relationship between exposure moisture content, moisture diffusion, and crosslink density on the crosslinking front dynamics in room temperature vulcanizing poly(dimethyl siloxane).
\end{abstract}

\section{Introduction}

Silicones or polysiloxanes possess exceptional properties and high durability regarding heat, weather aging, and moisture and chemical degradation. Silicones are therefore widely used in different fields, for example in building industry as sealing agents, release liners or coatings [1], in electronics as insulating coatings [2,3] or dielectric layers in pressure sensors [4], in microfluidic devices [5-8], in technological membranes [9-11], in dentistry [12], and in medical products such as finger joints and breast implants [13-15]. To reach their final state and shape of application, silicones are vulcanized from a viscous paste into an elastic rubber. The responsible crosslinking mechanism can be triggered in several ways, for example with crosslinking agents [16] or under the influence of increased temperature [10] or gamma-radiation [17-19]. A certain subgroup of silicones vulcanizes at room temperature under the influence of moisture. These so-called Room
Temperature Vulcanizing (RTV) silicones are often used as sealants. Before application, the most basic uncrosslinked RTV silicones contain chains of poly(dimethyl siloxane) (PDMS) with acetoxy end-groups. The crosslinking reaction is a two-step process and occurs when PDMS is brought in contact with a moisture source [20]. First, an acetoxy group is hydrolyzed into a silanol group, which results in the release of acetic acid:

$$
\begin{aligned}
& -\mathrm{O}-\mathrm{Si}\left(\mathrm{CH}_{3}\right)_{2}-\mathrm{O}-\stackrel{\mathrm{C}}{\mathrm{C}}-\mathrm{CH}_{3}+\mathrm{H}_{2} \mathrm{O} \rightarrow-\mathrm{O}-\mathrm{Si}\left(\mathrm{CH}_{3}\right)_{2}-\mathrm{OH} \\
& +\mathrm{H}_{3} \mathrm{C}-\stackrel{\mathrm{O}}{\mathrm{C}}-\mathrm{OH}
\end{aligned}
$$

Condensation of the silanol group results in crosslinking and additional release of acetic acid:

\footnotetext{
* Corresponding author.

E-mail address: 1.pel@tue.nl (L. Pel).
} 


$$
\begin{aligned}
& -\mathrm{O}-\mathrm{Si}\left(\mathrm{CH}_{3}\right)_{2}-\mathrm{O}-\stackrel{\mathrm{C}}{\mathrm{C}}-\mathrm{CH}_{3}+\mathrm{H}-\mathrm{O}-\mathrm{Si}\left(\mathrm{CH}_{3}\right)_{2}-\mathrm{O}-\rightarrow \\
& -\mathrm{O}-\mathrm{Si}\left(\mathrm{CH}_{3}\right)_{2}-\mathrm{O}-\mathrm{Si}\left(\mathrm{CH}_{3}\right)_{2}-\mathrm{O}-+\mathrm{H}_{3} \mathrm{C}-\stackrel{\mathrm{O}}{\mathrm{C}}-\mathrm{OH}
\end{aligned}
$$

The release of acetic acid is noticeable by a vinegary smell after application of the silicone paste.

The crosslinking of PDMS has been widely studied before using a variety of experimental techniques, e.g. infrared spectroscopic ellipsometry [21], Fourier transform infrared spectroscopy [10,16,19,22], Xray photoelectron spectroscopy [19], scanning electron microscopy [16], Raman spectroscopy [10,23], ${ }^{13} \mathrm{C}$ Nuclear Magnetic Resonance (NMR) spectroscopy [16,24], ${ }^{29} \mathrm{Si}$ NMR spectroscopy [14,24-26], ${ }^{1} \mathrm{H}$ NMR spectroscopy [16,19,22-26], and ${ }^{1} \mathrm{H}$ relaxometry [17,18,27-31]. Most often, the crosslinking of polymers in general and silicones in particular is studied by comparing uncrosslinked and crosslinked samples, by measuring the thickness-dependence of the crosslinking rate of a PDMS coating [21], or by measuring mechanical properties of a sample over time [32]. Spatial information on crosslinking in PDMS has been obtained before, but only on fully crosslinked samples [30,31]. Time-lapsed spatial information, however, can provide valuable information on the crosslinking dynamics of polymers, as demonstrated for alkyd coatings [33,34]. To the authors' knowledge, no similar studies on PDMS have been conducted so far.

The aim of this study is to relate the crosslinking dynamics in PDMS to the supply of moisture. To this end, we employ spatially resolved ${ }^{1} \mathrm{H}$ NMR to observe the movement of a crosslinking front, which becomes observable due to a difference in NMR transversal relaxation time between the crosslinked and uncrosslinked parts of the material. We relate the observed front velocity to the exposure condition and properties of the crosslinked rubber using a diffusion-reaction model. The moisture sorption capacity and diffusion coefficient of the crosslinked material are independently measured using Dynamic Vapor Sorption (DVS). The crosslink density is determined using swelling measurements of crosslinked rubber in toluene.

\section{Materials and methods}

\section{1. $N M R$}

The experimental setup to assess the crosslinking of a silicone rubber cylinder is shown in Fig. 1. A hollow cylindrical Teflon sample holder is used, the bottom half of which can be detached from the top. This allows us to cast silicone cylinders inside the sample holder, with a diameter of $20 \mathrm{~mm}$ and a height of $10 \mathrm{~mm}$. Bison ${ }^{\odot}$ mastic silicone sealant from a local do-it-yourself store is used in the experiments. The top surface of the sample is smoothened by scraping off surplus material. The experimental setup is designed such that air can be blown over

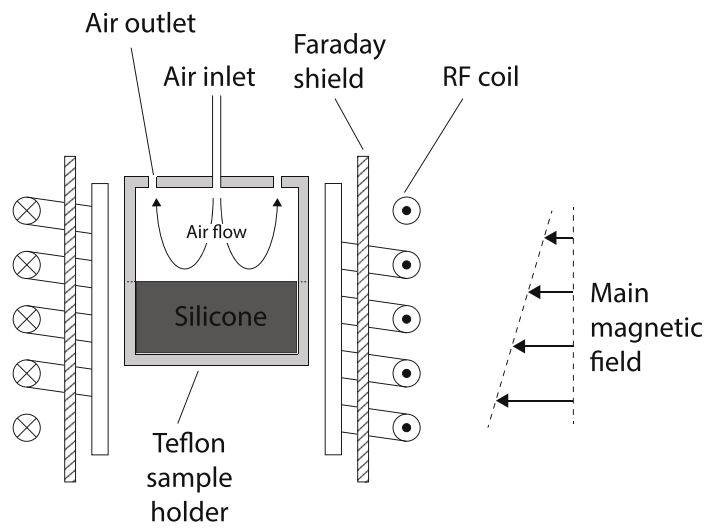

Fig. 1. Cross-section of the experimental NMR set-up used to measure one-dimensional hydrogen profiles of curing silicone cylinders. the top surface using a humidifier, which intermixes a dry and a wet air stream; their mixing proportions determine the relative humidity $(\mathrm{RH})$ of the resulting exposure air flow, which is verified by a Sensirion ${ }^{\odot} \mathrm{RH}$ sensor. Since the sides and bottom of the cast silicone cylinders are sealed off by the vapor-tight Teflon sample holder, we have created a one-dimensional experiment. Meanwhile, the signal distribution along the height of the sample is measured using NMR.

The key concept of NMR is that nuclei (e.g. ${ }^{1} \mathrm{H},{ }^{13} \mathrm{C}$ ) possess spin, and consequently have a magnetic dipole moment. In an externally applied magnetic field, these nuclei precess at a resonance frequency dependent on the measured nucleus $\left({ }^{1} \mathrm{H}\right.$ in our case) and the applied static magnetic field. This resonance condition allows the selective measurement of nuclei by applying suitably chosen radiofrequency (RF) pulses. Moreover, when a gradient in the static field is applied, the resonance condition is spatially dependent in the direction of the gradient. Accordingly the signal emitted by thin slices of approximately $1 \mathrm{~mm}$ can be determined separately by changing the resonance frequency of the RF pulses in steps.

The experiments described in this study are performed on a custombuilt NMR system, specifically designed for the quantitative measurement of moisture in porous materials. The system operates with an electromagnet producing a static magnetic field of $0.78 \mathrm{~T}$. To measure the spatially dependent signal, Anderson coils generate a magnetic field gradient of approximately $0.4 \mathrm{~T} / \mathrm{m}$ [35]. The complete setup is shown schematically in Fig. 1 . The Teflon sample holder containing the sample of interest is placed inside a solenoid coil to transmit and receive RF fields during the NMR experiments. A Faraday shield is placed between the coil and the sample to suppress the effects of a varying dielectric permittivity, thereby enabling quantitative measurements [36].

During an experiment, we perform a CPMG pulse sequence [37,38], which consists of a train of $180^{\circ} \mathrm{RF}$ pulses equally spaced in time after an initial $90^{\circ}$ excitation RF pulse at different frequencies under a constant vertical gradient in the magnetic field. Accordingly we measure the magnetization decay of thin slices along the height without moving the sample. To account for the decreasing sensitivity of the coil away from its center, the acquired signal distribution is divided by a reference profile obtained with a solution containing $0.1 \mathrm{M} \mathrm{CuSO}_{4}$ [39]. To enhance the signal-to-noise ratio, the signal of each slice is an average over 16 measurements. Furthermore, we use a repetition time of $2 \mathrm{~s}$, which is at least four times larger than the longitudinal relaxation time $T_{1}$ to ensure full recovery of the magnetization.

During the CPMG measurement, the decay of transversal magnetization $M$ (which is directly proportional to the received signal) can be represented by a sum of several modes:

$M(\tau)=\sum_{i} M_{i} e^{-\frac{\tau}{T_{2, i}}}$

where $\tau$ is the time after the initial manipulation of the magnetization by a $90^{\circ} \mathrm{RF}$ pulse ( $\tau=n t_{E}$, with $n$ the echo number and $t_{E}$ the echo time, which is $200 \mu \mathrm{s}$ in all experiments as to minimize the effects of diffusion on the magnetization decay), and $M_{i}$ and $T_{2, i}$ the magnetization and transversal relaxation time respectively corresponding to the $i$-th mode. The environment of the proton, e.g. the segmental mobility [40], influences its $T_{2}$ value. It has been demonstrated that network formation in the form of crosslinking affects the $T_{2}$ relaxation time, while the longitudinal relaxation time $T_{1}$ is invariant [27]. We can therefore expect to be able to image the spatial movement of the crosslinking reaction based on the $T_{2}$ relaxation time value.

\subsection{DVS}

The relationship between the ambient $\mathrm{RH}$ and the equilibrium moisture content (kg moisture $/ \mathrm{kg}$ dry material) of the vulcanized silicone rubber is determined using Dynamic Vapor Sorption (DVS). DVS relies on the accurate measurement of the mass of a sample placed in a 
humidity-controlled chamber upon step changes in the RH. Accordingly, the mass fraction of moisture in the sample can be determined for different equilibrium RH. To this end, silicone samples are casted in a small cylindrical aluminum sample container with an inner diameter of $5.5 \mathrm{~mm}$ and a height of $1.4 \mathrm{~mm}$, and crosslinked at different exposure conditions (crosslinking relative humidity $\mathrm{RH}_{\mathrm{CL}}=12 \%$, $\mathrm{RH}_{\mathrm{CL}}=85 \%$, and submersed in water). The completely crosslinked silicone rubber samples are dried in the oven at $50^{\circ} \mathrm{C}$ for one day before an actual experiment. Subsequently, the sample is placed on the balance of a DVS apparatus (TA Instruments Q5000 SA). The RH is varied in steps of $10 \%$, every $3 \mathrm{~h}$, except for the step from 90 to $98 \%$, where a waiting time of $5 \mathrm{~h}$ is used. Subsequently, the silicone sample is immersed in water to determine its liquid water-saturated moisture content. The moisture content time-evolution is fitted with a sum of three exponentials to retrieve the equilibrium moisture content for each step.

To determine the moisture diffusion coefficient from the silicone rubber moisture content increase over time, we first assume that we have one-dimensional Fickian diffusion with a constant diffusion coefficient. This is ensured by exposing the sample to small increments in RH. Furthermore, we presume low concentrations such that the system can be approached as ideal with negligible intermolecular interactions. Accordingly we can express the initial increase in fractional moisture content as:

$\frac{c(t)-c_{0}}{c_{e}-c_{0}} \cong 2 \sqrt{\frac{D t}{\pi d^{2}}}$,

where $c$ is the moisture content at time $t, c_{0}$ and $c_{e}$ the initial and final moisture content respectively, $D$ the moisture diffusion coefficient, and $d$ the sample thickness. With all variables but the diffusion coefficient known, we can retrieve the diffusion coefficient from the initial slope of the normalized mass-evolution on the $\sqrt{t}$-scale by data fitting.

\subsection{Swelling measurement}

To determine the average crosslink density of vulcanized silicone rubber, a silicone sample is immersed in a toluene solution [41]. Unlike water, toluene is absorbed in large quantities by vulcanized silicone [42,43], which results in substantial swelling of the silicone sample. At swelling equilibrium, the crosslink density $\gamma$ can be calculated as follows:

$\gamma=\frac{\rho}{M_{C L}}=-\frac{\ln (1-\varphi)+\varphi+\chi \varphi^{2}}{V_{T} \varphi^{1 / 3}}$,

where $\rho$ is the density of the unswollen crosslinked sample, $M_{C L}$ the average molecular weight between crosslinking sites, $\chi$ the interaction parameter of the polymer and the solvent $(0.465)$ [16], and $V_{T}$ the molar volume of toluene $\left(106.54 \mathrm{~cm}^{3} / \mathrm{mol}\right)$. The reciprocal of the volume increase $\varphi$ can be determined using the swollen and unswollen mass of the sample:

$\varphi=\frac{1}{\frac{\rho}{\rho_{T}} \frac{w_{s}-w_{0}}{w_{0}}+1}$,

where $\rho_{T}$ is the density of toluene $\left(870 \mathrm{~kg} / \mathrm{m}^{3}\right)$, and $w_{s}$ and $w_{O}$ the weight of the swollen and unswollen sample respectively.

\section{Results and discussion}

\subsection{DVS}

The mass percentage of water over time during step changes in the ambient RH is demonstrated in Fig. 2a. As can be seen, in most cases the silicone sample quickly attains a constant value following a step change in the RH. Nevertheless, the time-evolution of the mass fraction after each step is fitted with a sum of three exponentials to retrieve the eventual equilibrium value. This equilibrium moisture content $c_{e}(\mathrm{~kg}$ moisture/kg dry material) is shown in the sorption curve in Fig. 2b as a function of RH. The curve is approximately linear between an RH of $10 \%$ and $80 \%$, with a steep increase for higher $\mathrm{RH}$. This is consistent with sorption isotherms of water in PDMS reported in the literature [9,44-47] and corresponds to systems in which sorbate-sorbent interactions are relatively weak compared to sorbate-sorbate interactions. Furthermore, the liquid water-saturated moisture content is approximately the value corresponding to an extrapolation to $\mathrm{RH}=100 \%$. Up to an $\mathrm{RH}$ of $80 \%$, only minor differences in equilibrium moisture content are observed between the different samples. At high RH a larger sorption capacity of the sample which was vulcanized while submersed in water is observed; a possible explanation is presented in section 3.6.

\subsection{Magnetization decay}

After being cast into the Teflon sample holder, the silicone cylinder is exposed to a moisture source in the form of air with a certain RH or a water layer. Meanwhile, the local magnetization decay is measured at different positions along the axis of the cylinder. An example of the magnetization decay at a distance of $5 \mathrm{~mm}$ from the exposed surface at different exposure times is shown in Fig. 3a for a sample exposed to an $\mathrm{RH}$ of $85 \%$. As can be seen, the initial slope of the decay becomes steeper at longer exposure times, which can be attributed to the contribution of protons with a lower $T_{2}$ relaxation time. Laplace inversion of the decay provides the proton density distribution, as demonstrated in Fig. 3b. As can be seen, the initial $T_{2}$-distribution consists of a single peak around $100 \mathrm{~ms}$. A second peak around $2 \mathrm{~ms}$ emerges over time, clearly visible in the final $T_{2}$-distribution. This second peak arises as a result of the crosslinking reaction; protons neighboring the crosslinking site become more restrained in their movement, which results in a lower $T_{2}$ relaxation time. A similar bimodal decay of the magnetization in crosslinked PDMS has been observed before [30,31].

The decrease in area under the initial peak in the $T_{2}$-distribution over time is observable in Fig. 3b. Simultaneously, the second peak at a lower $T_{2}$ value emerges, the area of which increases over time. The area under the peak corresponding to a high $T_{2}$ relative to the initial area is shown in Fig. 4 as a function of the relative area under the peak corresponding to a low $T_{2}$. As can be seen, the decrease in signal of high $T_{2}$ is directly related to the increase in signal of low $T_{2}$. This is a clear indication that crosslinking occurs, since the total amount of signal remains equal, and only the $T_{2}$ relaxation time of a certain amount of protons changes.

\subsection{Crosslinking front movement}

In the previous subsection we demonstrated that the magnetization decay is affected by the occurring crosslinking reaction. Since we measure the local magnetization decay at different positions along the height of the cylinder, we are able to distinguish between crosslinked and uncrosslinked parts of the material. In this subsection we present two different approaches to characterize the spatial distribution of crosslinked material over time.

The most straightforward approach comprises the presentation of the signal distribution corresponding to different $\tau$. This should be interpreted as follows: for $\tau$ smaller than the shortest $T_{2}$-component, i.e. shortly after initial excitation of the protons, $T_{2}$-relaxation is negligible. Hence all protons participate in the received signal and the distribution includes all protons present in the sample. By increasing $\tau$, we arrive at a point where we have lost the contribution of the short $T_{2}$-components, whereas long $T_{2}$-components still contribute to the signal. For $\tau$ much larger than the largest $T_{2}$-component, we lose all signal. The above is illustrated in Fig. 5a as spatial signal distributions corresponding to different $\tau$, at different measurement times, during a typical experiment (exposure $\mathrm{RH}=85 \%$ ). The signal distributions corresponding to $\tau=200 \mu$ s (i.e. the first acquired echo of the CPMG pule sequence) present the spatial arrangements of the total number of protons over 

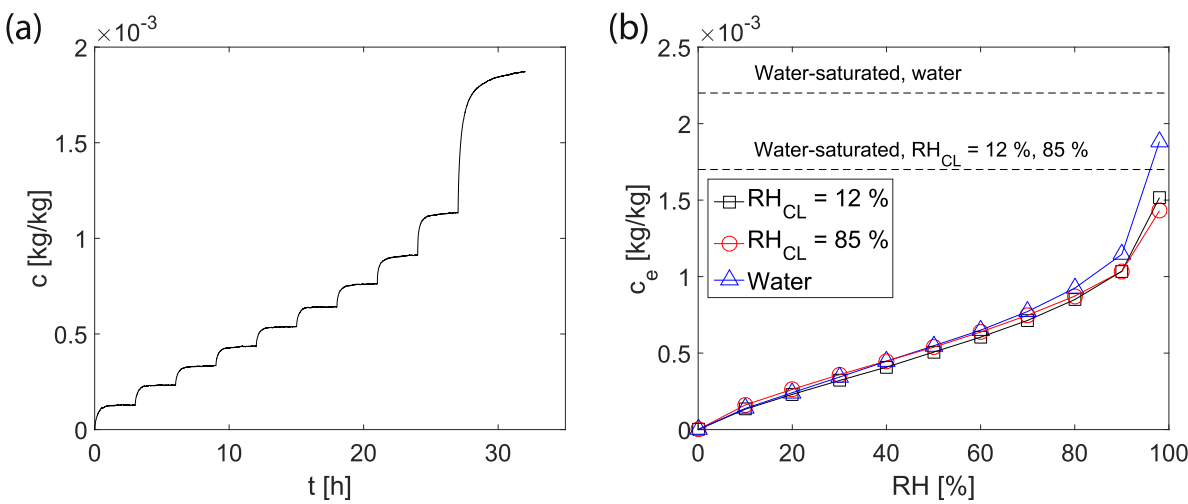

Fig. 2. (a) The moisture content $\mathrm{c}$ of a silicone cylinder, which was vulcanized while submersed in water, during step changes in the ambient RH. (b) The equilibrium moisture content $c_{e}$ as a function of the $\mathrm{RH}$, for samples vulcanized at different exposure conditions $\left(R H_{C L}=12 \%, R H_{C L}=85 \%\right.$, and submersed in water). The liquid water-saturated moisture content is shown for the different samples as horizontal dashed lines.
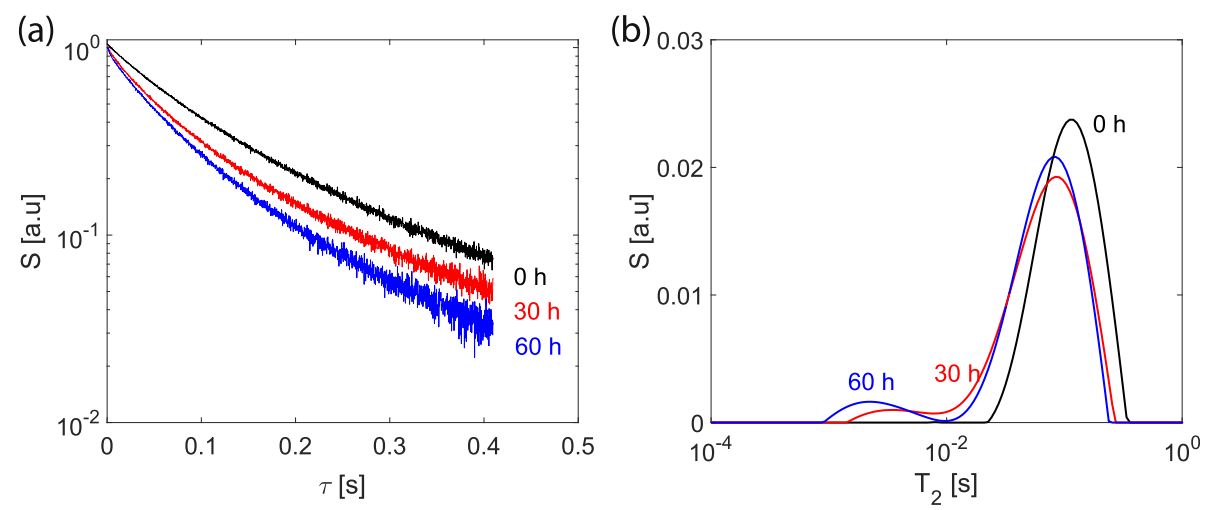

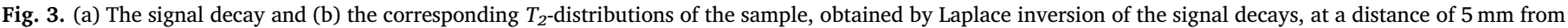
the exposed surface at different exposure times.

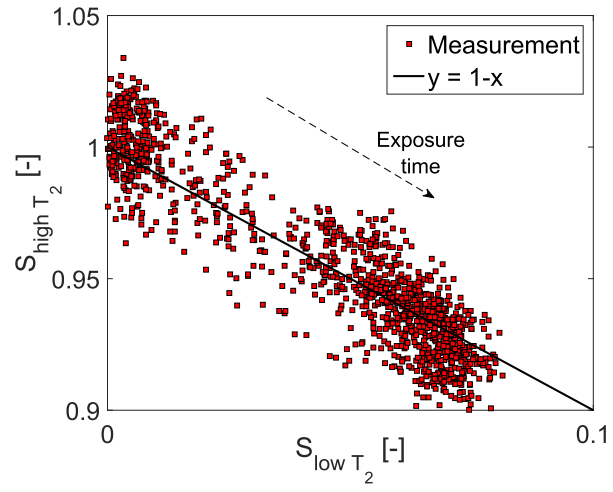

Fig. 4. The fraction of the total signal attributed to spins with high $T_{2}$ as a function of the fraction attributed to spins with low $T_{2}$. time. The total signal displays no significant changes over time; the conservation of the protons during the experiment was already concluded from Fig. 4a. A slight compaction of the sample, however, is observed, which is illustrated by the inward movement of the left boundary. This feature was independently assessed by measuring the thickness of a silicone film over time using the probe of a Mettler Toledo TMA/SDTA 841e system. The film with a thickness of approximately $1 \mathrm{~mm}$ was placed between two cylindrical silica plates and exposed to an air flow with an $\mathrm{RH}$ of $30 \%$. During vulcanization, the sample compacted $30 \mu \mathrm{m}$, which, for a sample thickness of $10 \mathrm{~mm}$, extrapolates to a compaction of $\sim 300 \mu \mathrm{m}$. This is roughly in agreement with the observed compaction in Fig. 5a.

To demonstrate the spatial arrangement of crosslinked and uncrosslinked material over time, we also present signal distributions corresponding to $\tau=40 \mathrm{~ms}, 100 \mathrm{~ms}$, and $200 \mathrm{~ms}$ (the $200^{\text {th }}$, the $500^{\text {th }}$, and the $1000^{\text {th }}$ echo respectively) in Fig. 5a. These values for $\tau$ are much larger than the short $T_{2}$-components in Fig. $3 \mathrm{~b}$ with a peak around $2 \mathrm{~ms}$. By choosing sufficiently large values for $\tau$, we eliminate the (a)

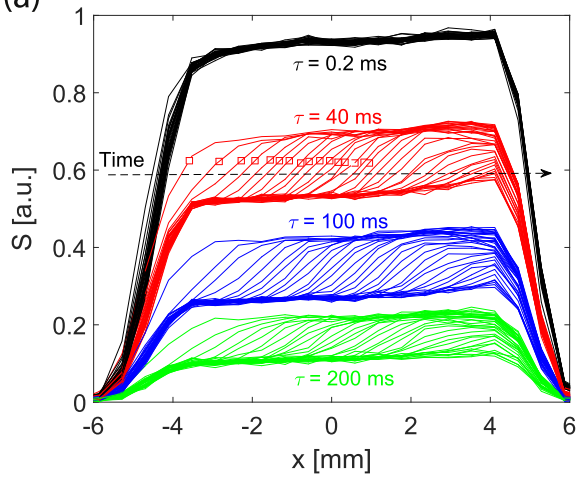

(b)

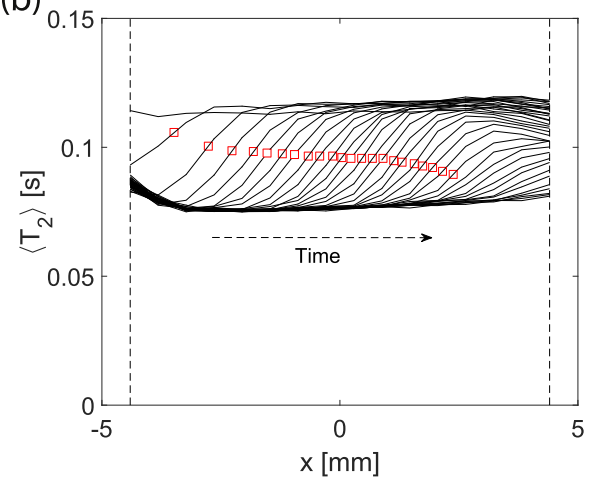

Fig. 5. (a) The spatial distribution of the signal at different measurement times during exposure to air with an RH of $85 \%$ (on the left side of the figure), for different echo times $(\tau=0.2 \mathrm{~ms}, 40 \mathrm{~ms}, 100 \mathrm{~ms}$, and $200 \mathrm{~ms}$ ). Time between subsequent distributions is $2 \mathrm{~h}$. The front position is shown with square markers in the signal distribution corresponding to $\tau=40 \mathrm{~ms}$. (b) The spatial distribution of the arithmetic mean of the $T_{2}$ relaxation time at different measurement times. 
contribution of the short $T_{2}$-components from the signal. The profiles corresponding to large $\tau$ in Fig. 5a therefore present the distribution of uncrosslinked material. Here, we observe a clear boundary between a lower and a higher concentration of high $T_{2}$-components, which indirectly also represents a boundary between crosslinked silicone rubber located to the left and uncrosslinked silicone to the right. The boundary thus marks the spatial location of the crosslinking reaction, which we denote as the crosslinking front. This front displaces over time from left to right in all three distributions until it reaches the back of the sample. In the end, the sample is crosslinked homogeneously, with a nearly constant final signal distribution.

Alternatively, we can characterize the local magnetization decay by calculating an arithmetic mean $T_{2}$ relaxation time as [48]:

$\left\langle T_{2}\right\rangle=\int_{0}^{\infty} \frac{M(\tau)}{M_{0}} d \tau$,

where $M_{O}$ is the magnetization at $\tau=0$. As already observed in Fig. 3a, crosslinked material exhibits a faster magnetization decay compared to uncrosslinked material. This results in a shorter arithmetic mean $T_{2}$, which allows us to distinguish between the crosslinked and uncrosslinked parts of the material. Accordingly we can present distributions of $\left\langle T_{2}\right\rangle$ at different exposure times, as illustrated in Fig. 5b. Similar to the signal distributions corresponding to different high $\tau$, we observe a sharp boundary between a lower $\left\langle T_{2}\right\rangle$ on the left and a higher $\left\langle T_{2}\right\rangle$ on the right. This boundary, again, indirectly marks the crosslinking front location which separates the crosslinked and uncrosslinked material.

The presence of a sharp front suggests that moisture diffusion towards the front is the limiting factor in the crosslinking process, meaning that the crosslinking reaction occurs quasi-instantaneously. We will use this observation in the next subsection to formulate a diffusion-reaction model for the analysis of the front displacement over time. As a first step, we can define the front position as the location where the signal is an average of the values to the left and the right of the front. For illustrative purposes, the front position is added to the signal distributions corresponding to $\tau=40 \mathrm{~ms}$ and in the $\left\langle T_{2}\right\rangle$-distributions in Fig. 5a and b respectively. The definition of the front position appears arbitrary; alternatively, one could choose a fixed value to determine the front position. This, however, has no significant influence on the front position over time. The front position as a function of time for the experiment displayed in Fig. 5 is shown in Fig. 6. Different distributions have been used to determine the front position, which all produce the same time-evolution. In all cases the front displacement is proportional to the square root of time, which is elucidated by the inset illustrating the linearity on a square-root-of-time scale.

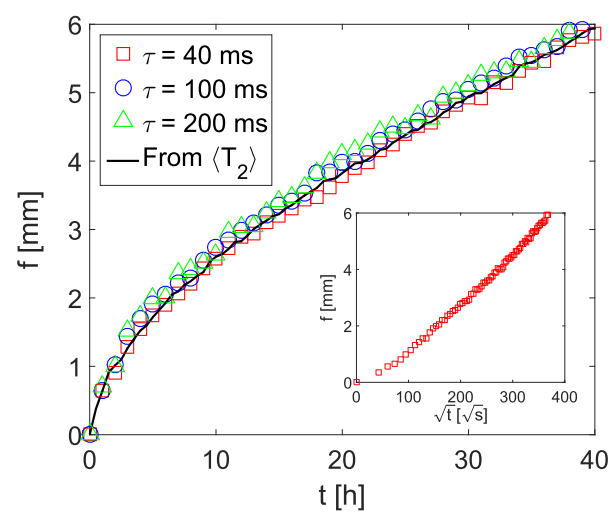

Fig. 6. The front position $f$ as a function of time for a sample exposed to air with an RH of $85 \%$. Different distributions have been used to determine f: the signal distributions corresponding to $\tau=40 \mathrm{~ms}, 100 \mathrm{~ms}$, and $200 \mathrm{~ms}$, and the $\left\langle T_{2}\right\rangle^{-}$ distributions. The figure inset shows the front position as a function of $\sqrt{t}$ determined from the signal distributions corresponding to $\tau=40 \mathrm{~ms}$.
As mentioned before, the crosslinking reaction relies on the presence of moisture. Hence it can be expected that, if the crosslinking reaction occurs quasi-instantaneously, the crosslinking front movement will depend on the moisture supply. This is illustrated in Fig. 7a, where the front position is shown during exposure to air with a changing $\mathrm{RH}$. When dry air is blown over the sample, the signal distribution remains unchanged and no front is formed. Elevating the RH to $85 \%$ results in the emergence of a crosslinking front, which rapidly displaces towards the unexposed surface. Subsequently lowering the $\mathrm{RH}$ to a value of $45 \%$ decelerates the front again. For illustrative purposes, we additionally present the crosslinking front position in a sample exposed to a cyclic fluctuation in RH in Fig. 7b. The sample is first exposed to a constant $\mathrm{RH}$ of $10 \%$ for $4 \mathrm{~h}$, after which the $\mathrm{RH}$ is varied in a cosine manner with a period of $8 \mathrm{~h}$ between $10 \%$ and $90 \%$. As can be seen, the front movement alternately accelerates and decelerates, depending on the exposure $\mathrm{RH}$, with a high velocity during high $\mathrm{RH}$ and vice versa.

Fig. 7 demonstrates the dependence of the crosslinking front velocity on the exposure RH in a single sample. Similarly, the front position as a function of the square root of time for samples exposed to different exposure conditions (constant $\mathrm{RH}$ and submersed in water) is demonstrated in Fig. 8a. As can be seen, the front displacement enhances with exposure $\mathrm{RH}$, and has the highest value when submersed in water. The square-root-of-time dependence is illustrated for all cases by linear fits to the front position. To explain this $\sqrt{t}$-dependence, a diffusion-reaction model similar to the one by Erich et al. [33] is introduced.

\subsection{Diffusion-reaction model}

For the description of the crosslinking front movement, we assume a semi-infinite one-dimensional geometry. Accordingly, the description is valid as long as the crosslinking front does not reach the back of the sample. First, the moisture mass flux $J$ through the crosslinked silicone is described by the diffusion equation:

$J=-D \frac{\partial c}{\partial x}$

where $D$ is the diffusion coefficient of moisture in silicone [2], $c$ the mass-based moisture content, and $x$ the position along the height of the cylinder. We assume here that the moisture is consumed immediately in the crosslinking reaction. The front velocity is therefore limited by the supply of moisture, i.e. the moisture flux towards the front, and the amount of water consumed in the formation of a crosslink site. Hence, the front velocity can be expressed as

$\frac{d f}{d t}=v J$,

where $f$ is the front position and $t$ is time. The mass of crosslinked silicone per mass of water consumed in the reaction is denoted as $\nu$ and can be expressed as

$\nu=\frac{\rho}{M_{W} n \gamma}$,

where $\rho$ is the vulcanized silicone rubber density, $M_{W}$ the molar mass of water, $n$ the moles of water consumed per mole of crosslinks created (which equals unity if Eqs. (1) and (2) are followed exactly), and $\gamma$ the crosslink density. At the exposed surface, the moisture concentration is fixed at a value $c_{0}$, which is the equilibrium value corresponding to the exposure condition. At the front position, all water is consumed instantaneously, resulting in a zero concentration at the front. The concentration difference thus has a constant value of $c_{o}$, the length over which this difference acts, i.e. the front position $f$, changes over time. Eq. (8) can thus be rewritten as:

$J=D \frac{c_{0}}{f(t)-f_{0}}$,

where $f_{o}$ is the initial front position. Substitution of Eq. (11) into Eq. (9) 
(a)

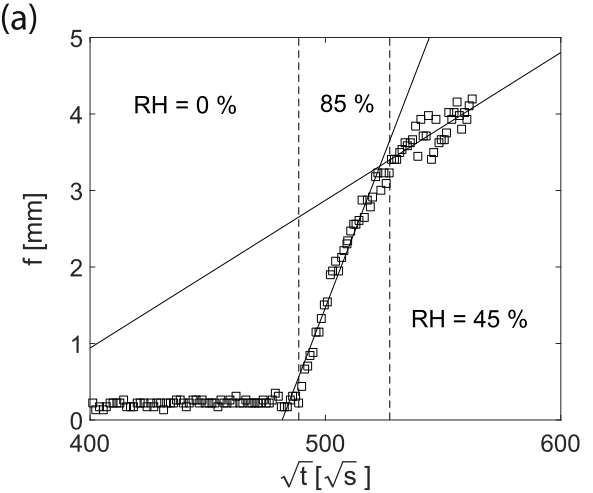

(b)

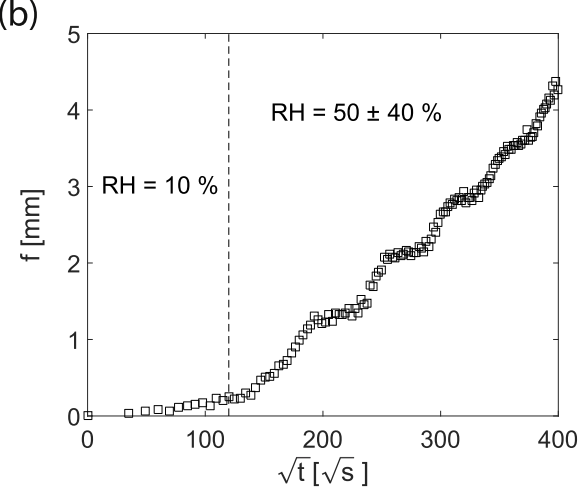

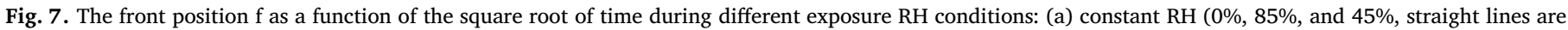
linear fits to the front position), (b) initially constant (10\%), then varied in a cosine manner $(50 \pm 40 \%)$.
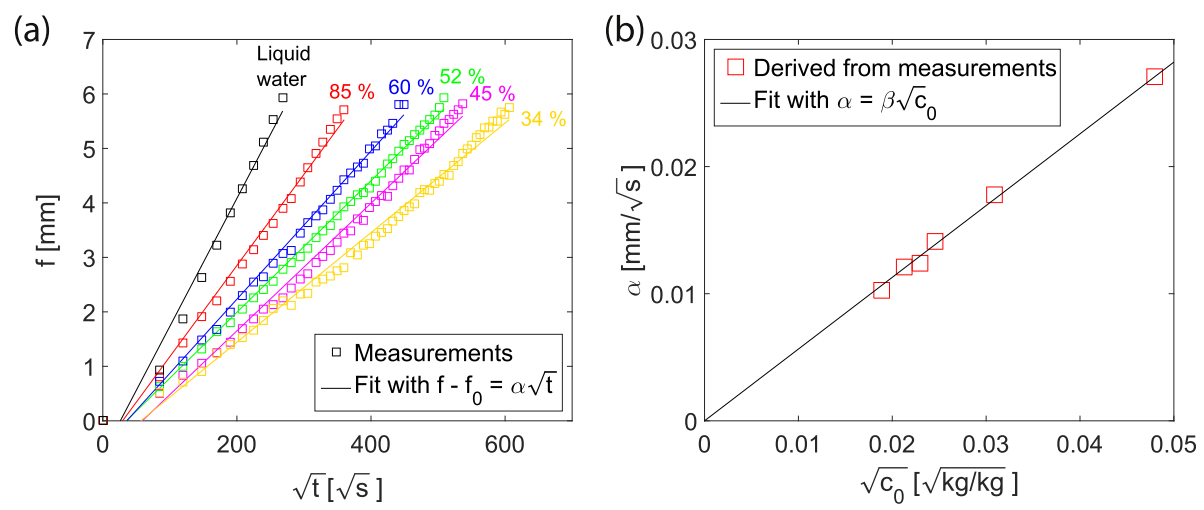

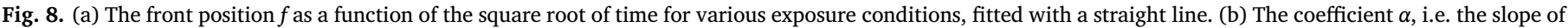
the linear fits in (a) as a function of the square root of the exposure moisture content $c_{0}$.

and subsequent integration yields

$f(t)-f_{0}=\sqrt{2 v D c_{0}\left(t-t_{0}\right)}$,

where $t_{0}$ is the time corresponding to the front position $f_{o}$.

The diffusion-reaction model predicts the front to displace with the square root of time, which is in agreement with our experimental results. We can thus fit the front position over time with $f-f_{o}=\alpha \sqrt{t}$, as demonstrated in Fig. 8a. According to Eq. (12), the slope of the fit on the $\sqrt{t}$-scale is proportional to the square root of the exposure equilibrium moisture content, i.e. $\alpha=\sqrt{2 \nu D c_{0}}$. The latter is verified in Fig. 8b, where we present the coefficient $\alpha$ as a function of $\sqrt{c_{0}}$. Use has been made of the moisture sorption curve in Fig. $2 \mathrm{~b}$ to relate exposure condition to $c_{0}$. Linear proportionality exists between $\alpha$ and $\sqrt{c_{0}}$, which demonstrates the validity of the diffusion-reaction model. Alternatively we can scale the front dynamics of our experiments in two ways, both involving $c_{O}$ and based on Eq. (12). Time can be scaled to arrive at a scaled time $\sqrt{c_{0} t}$. Similarly, the front position can be rescaled to arrive at $f / \sqrt{c_{0}}$. Both scaling procedures result in one single master curve for all experiments, as demonstrated in Fig. 9. The slope of the linear fit is then proportional to the square root of the diffusion coefficient $D$ and $\nu$, i.e. $\beta=\sqrt{2 v D}$. This parameter $\sqrt{2 v D}$ can be seen as a front diffusivity, with derived values of $0.52,0.54$, and $0.56 \mathrm{~mm} / \sqrt{\mathrm{s}}$ from the fits to the data in Figs. 8b, 9a and 9b respectively. The constant values for $\beta$ derived from the fits to the front position illustrate that the product $\nu D$ is independent of $c_{0}$, which will be more elaborately studied in the next subsection.

\subsection{Crosslinking front diffusivity and crosslink density}

The direct observation of the crosslinking front displacement revealed that the product $\nu D$ is approximately constant. To determine whether the two independent coefficients $v$ and $D$ are constant values, first the crosslink density $\gamma$ of silicone samples which were vulcanized at different exposure conditions is shown in Fig. 10. The crosslink density decreases slightly with an increase in the exposure moisture content $c_{0}$. Nevertheless, the decrease in crosslink density is relatively minor over the range considered here.

With the directly measured crosslink densities and the derived front diffusivity $(\sqrt{2 \nu D}=0.54 \mathrm{~mm} / \sqrt{s})$, we can derive the moisture diffusion coefficient as a function of $c_{O}$ using Eq. (10) and values for $\rho, n$, and $M_{w}$ of $1020 \mathrm{~kg} / \mathrm{m}^{3}, 1$, and $0.018 \mathrm{~kg} / \mathrm{mol}$ respectively. The resulting dependence of $D$ on $c_{O}$ is demonstrated in Fig. 11. The diffusion coefficient decreases slightly from $1.7 \cdot 10^{-9}$ to $1.5 \cdot 10^{-9} \mathrm{~m}^{2} / \mathrm{s}$, which is in good agreement with the constant values (i.e. not dependent on the moisture content) between $1.6 \cdot 10^{-9}$ and $2.2 \cdot 10^{-9} \mathrm{~m}^{2} / \mathrm{s}$ found by Watson and Baron [49] for different PDMS films. The diffusion coefficient of moisture in crosslinked silicone as derived from DVS experiments with small cylindrical samples is displayed in Fig. 11 too. As can be seen, these values are lower than derived from the crosslinking front dynamics, although of the same order of magnitude. No significant differences between the various samples are observed. However, a moisture content-dependence in the diffusion coefficient is observed, with lower values at both low and high moisture content. This is qualitatively similar to the inverse of the sorption curve slope in Fig. 2 b. Falling diffusion coefficients at high moisture content have been measured before [45,50], as well as constant diffusion coefficients [49]. Here we are satisfied with the order of magnitude of the diffusion coefficient around $1 \cdot 10^{-9} \mathrm{~m}^{2} / \mathrm{s}$. Despite several simplifying assumptions made in the derivation of the moisture diffusion coefficient from the front dynamics in our NMR experiments, retrieved values are in reasonable agreement with the DVS values. The latter confirms the validity of our diffusion-reaction model to describe crosslinking in 

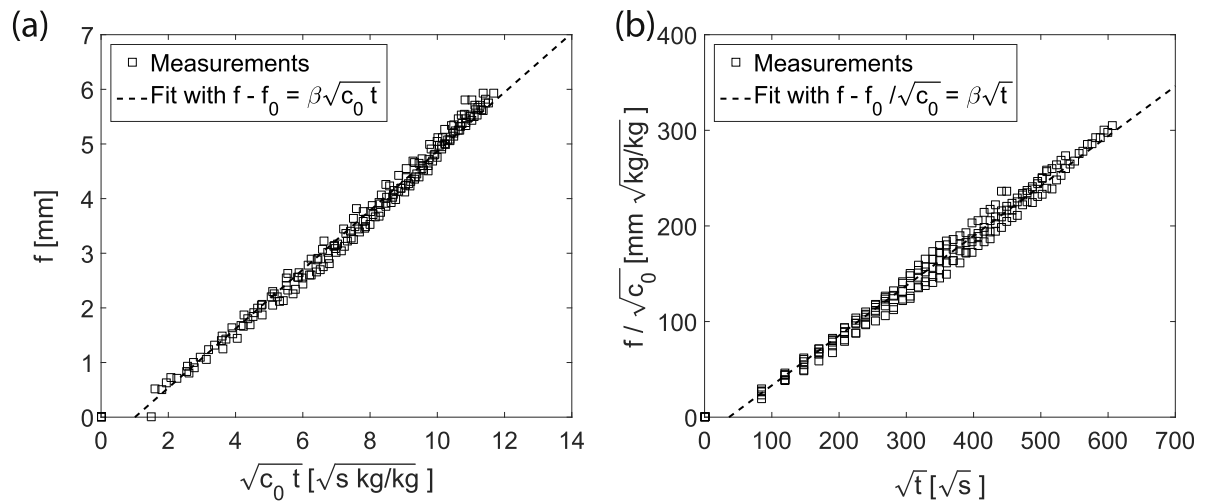

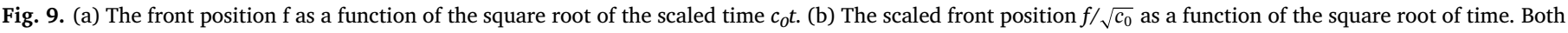
master curves are fitted linearly to derive the slope, which is proportional to the square root of $\nu$ and $D$.

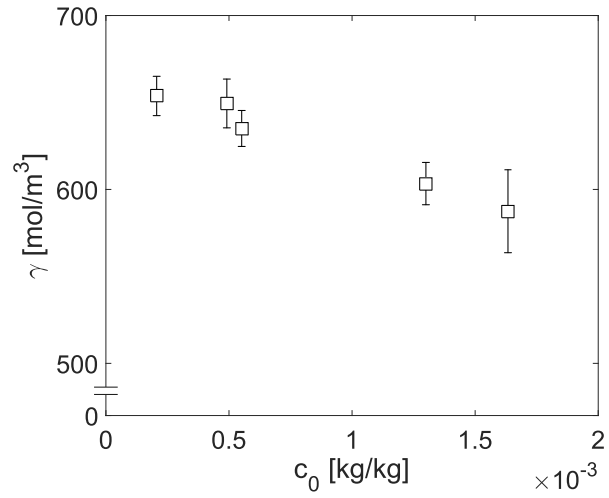

Fig. 10. The crosslink density $\gamma$ as a function of the moisture content $c_{O}$ corresponding to the environment in which the silicone rubber was vulcanized.

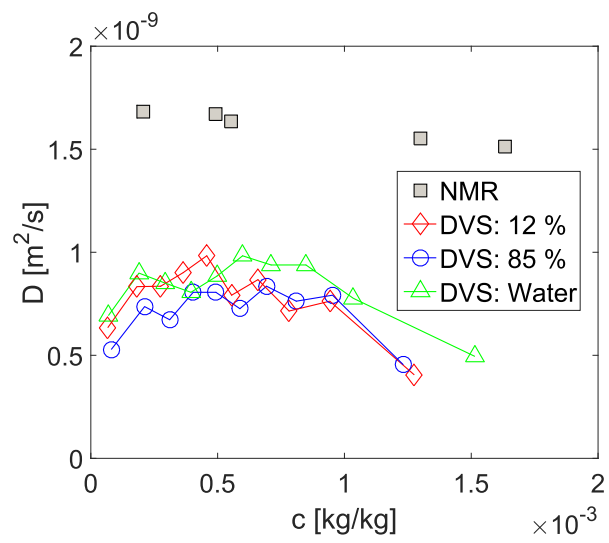

Fig. 11. The moisture diffusion coefficient in crosslinked silicone rubber as a function of moisture content as derived from NMR experiments and from DVS moisture sorption data.

PDMS.

With the crosslink density and the diffusion coefficient in Figs. 10 and 11 , we can calculate a value for the front diffusivity $\sqrt{2 \nu D}$ from directly measured values. Assuming parameter values of $1025 \mathrm{~kg} / \mathrm{m}^{3}$, $600 \mathrm{~mol} / \mathrm{m}^{3}$ and $1 \cdot 10^{-9} \mathrm{~m}^{2} / \mathrm{s}$ for the density $\rho$, the crosslink density $\gamma$, and diffusion coefficient $D$, we arrive at $\sqrt{2 \nu D}=0.43 \mathrm{~mm} / \sqrt{s}$. The reasonable agreement with the fits to the data in Figs. $8 \mathrm{~b}, 9 \mathrm{a}$ and $9 \mathrm{~b}$ $(\sqrt{2 v D}=0.52-0.56 \mathrm{~mm} / \sqrt{\mathrm{s}})$ confirms the validity of the simple diffusion-reaction model to describe crosslinking dynamics in PDMS.

\subsection{Crosslink effectiveness}

In the derivation of the diffusion coefficient from the measured front dynamics, we assumed the moles of water consumed per formed crosslink $n$ to be independent of exposure moisture content and equal to unity. In conjunction with the slight decrease in $\gamma$ with exposure moisture content, this accordingly resulted in a slight decrease in diffusion coefficient with $c_{0}$. Judging from the two-step crosslinking reactions displayed in (1) and (2) it is reasonable to assume that $n=1$, provided that half of the acetoxy groups hydrolyze into silanols in step (1), where they react with the remaining half of the acetoxy groups to form crosslinks. It is, however, possible that with a higher $c_{o}$ during crosslinking, an abundance of acetoxy groups is hydrolyzed into silanols, deploying the acetoxy source for further condensation. As a result, less crosslinks are formed due to a surplus of silanols. This is in accordance with previous findings of an increase in the amount of hydroxyl groups with vulcanization RH [51], which could potentially explain the higher sorption capacity at high $\mathrm{RH}$ of the sample vulcanized while submersed in water (see Fig. 2b). The amount of water consumed in the reactions is therefore presumably independent of the exposure condition. The effectiveness of the reaction, however, decreases with an increase in $c_{0}$. Hence we can express the moles of water consumed per mole of created crosslinks $n=m / \phi$, with $m$ the moles of water consumed in the two-step reaction $(m=1)$ and $\phi$ the effectiveness of the reaction $(\phi \leq 1)$. The minor change in crosslink density with $c_{0}$, however, results in an only slightly decreasing effectiveness.

\section{Conclusions}

Exploiting the difference in transversal relaxation time between uncrosslinked and crosslinked silicone rubber, we have demonstrated the observability of a crosslinking front movement using spatially resolved ${ }^{1} \mathrm{H}$ NMR relaxometry. This crosslinking front, which displaces away from the exposed surface in proportion to the square root of time, separates the crosslinked and uncrosslinked parts of the material. The presence of the front indicates that moisture transport toward the front is the limiting step in the crosslinking process. The front velocity is hence enhanced with an increase in exposure moisture concentration.

The observed front displacement can be satisfactorily described using a diffusion-reaction model. Moisture diffuses through the crosslinked part of the material towards the crosslinking front, where the supplied moisture is consumed immediately. The observed square-rootof-time dependence of the front position is supported by the model, as well as its proportionality to the square root of the exposure moisture concentration. Accordingly the front displacement can be scaled based on the exposure moisture content for experiments performed at different conditions. The front diffusivity derived from the resulting scaled front displacement is in reasonable agreement with the front diffusivity 
calculated using directly measured material properties. This marks the validity of the diffusion-reaction model and confirms the influence of moisture supply, moisture diffusion, and crosslink density on the crosslinking front dynamics.

\section{Notes}

The authors declare no competing financial interest.

\section{Acknowledgements}

The authors would like to thank J.H.J. Dalderop and J.J. Noijen for their technical support, and H.H.J.M. van Helvoirt and G. Fransen for the preparation of the sample holder. The work described in this paper has been carried out in the Darcy Center for porous media research and technology.

\section{References}

[1] L. Mathivanan, S. Radhakrishna, Protection of steel structures in industries with epoxy-silicone based coatings, Anti-Corros. Method. M. 45 (1998) 301-305 https:// doi.org/10.1108/00035599810234597.

[2] J.L. Mrotek, M.J. Matthewson, C.R. Kurkjian, Diffusion of moisture through optical fiber coatings, J. Lightwave Technol. 19 (2001) 988-993 https://doi.org/10.1109/ 50.933294.

[3] X. Chen, S. Zhou, B. You, L. Wu, Mechanical properties and thermal stability of ambient-cured thick polysiloxane coatings prepared by a sol-gel process of organoalkoxysilanes, Prog. Org. Coating 74 (2012) 540-548 https://doi.org/10.1016/j porgcoat.2012.01.021.

[4] Y. Peng, S. Xiao, J. Yang, J. Lin, W. Yuan, W. Gu, X. Wu, Z. Cui, The elastic microstructures of inkjet printed polydimethylsiloxane as the patterned dielectric layer for pressure sensors, Appl. Phys. Lett. 110 (2017) 261904 https://doi.org/10 $1063 / 1.4990528$.

[5] H. Sasaki, H. Onoe, T. Osaki, R. Kawano, S. Takeuchi, Parylene-coating in PDMS microfluidic channels prevents the absorption of fluorescent dyes, Sensor. Actuator. B Chem. 150 (2010) 478-482 https://doi.org/10.1016/j.snb.2010.07.021.

[6] M. Kim, Y. Huang, K. Choi, C.H. Hidrovo, The improved resistance of PDMS to pressure-induced deformation and chemical solvent swelling for microfluidic devices, Microelectron. Eng. 124 (2014) 66-75 https://doi.org/10.1016/j.mee.2014 04.041 .

[7] S. Halldrosson, E. Lucumi, R. Gómez-Sjöberg, R.M.T. Fleming, Advantages and challenges of microfluidic cell culture in polydimethylsiloxane devices, Biosens. Bioelectron. 63 (2015) 218-231 https://doi.org/10.1016/j.bios.2014.07.029.

[8] B.J. van Meer, H. de Vries, K.S.A. Firth, J. van Weerd, L.G.J. Tertoolen, H.B.J. Karperien, P. Jonkheijm, C. Denning, A.P. IJzerman, C.L. Mummery, Small molecule absorption by PDMS in the context of drug response bioassays, Biochem. Bioph. Res. Co. 482 (2017) 323-328 https://doi.org/10.1016/j.bbrc.2016.11.062.

[9] C.A. Scholes, G.W. Stevens, S.E. Kentish, The effect of hydrogen sulfide, carbon monoxide and water on the performance of a PDMS membrane in carbon dioxide/ nitrogen separation, J. Membr. Sci. 350 (2010) 189-199 https://doi.org/10.1016/j. memsci.2009.12.027.

[10] K. Berean, J.Z. Ou, M. Nour, K. Latham, C. McSweeney, D. Paull, A. Halim, S. Kentish, C.M. Doherty, A.J. Hill, K. Kalatar-zadeh, The effect of crosslinking temperature on the permeability of PDMS membranes: evidence of extraordinary $\mathrm{CO}_{2}$ and $\mathrm{CH}_{4}$ gas permeation, Separ. Purif. Technol. 122 (2014) 96-104 https://doi. org/10.1016/j.seppur.2013.11.006.

[11] C.A. Scholes, S.E. Kentish, G.W. Stevens, D. deMontigny, Asymmetric composite PDMS membrane contactors for desorption of $\mathrm{CO} 2$ from monoethanolamine, Int. J. Greenh. Gas Con. 55 (2016) 195-201 https://doi.org/10.1016/j.ijggc. 2016.10.008.

[12] S.J. Garner, A.H. Nobbs, L.M. McNally, M.E. Barbour, An antifungal coating fo dental silicones composed of chlorhexidine nanoparticles, J. Dent. 43 (2015) 362-372 https://doi.org/10.1016/j.jdent.2014.12.005.

[13] J. Sanchéz-Guerrero, G.A. Colditz, E.W. Karlson, D.J. Hunter, F. Speizer, M.H. Liang, Silicone breast implants and the risk of connective-tissue diseases and symptoms, N. Engl. J. Med. (1995) 1666-1670 https://doi.org/10.1056/ NEJM199506223322502.

[14] R.B. Taylor, D.E. Eldred, G. Kim, J.M. Curtis, H.J. Brandon, P.C. Klykken, Assessment of silicone gel breast implant biodurability by NMR and EDS techniques, J. Biomed. Mater. Res. A 85 (2007) 684-691 https://doi.org/10.1002/jbm.a 31589 .

[15] A. Colas, J. Curtis, Silicones, in: K. Modjarrad, S. Ebnesajjad (Eds.), Handbook of Polymer Applications in Medicine and Medical Devices, William Andrew Publishing, Oxford, 2013, pp. 131-143 https://doi.org/10.1016/B978-0-323 22805-3.00007-4.

[16] Q. Li, X. Huang, H. Liu, S. Shang, Z. Song, J. Song, Properties enhancement of room temperature vulcanized silicone rubber by rosin modified aminopropyltriethoxysilane as a cross-linking agent, ACS Sustain. Chem. Eng. 5 (2017) 10002-10010 https://doi.org/10.1021/acssuschemeng.7b01943.

[17] R. Folland, A. Charlesby, Pulsed N.M.R. studies of radiation-induced crosslinking and gel formation in linear polydimethylsiloxane, Int. J. Radiat. Phys. Chem. 8
(1976) 555-562 https://doi.org/10.1016/0020-7055(76)90022-X.

[18] R.S. Maxwell, R. Cohenour, W. Sung, D. Solyom, M. Patel, The effects of $\gamma$-radiation on the thermal, mechanical, and segmental dynamics of a silica filled, room temperature vulcanized polysiloxane rubber, Polym. Degrad. Stabil. 80 (2003) 443-450 https://doi.org/10.1016/S0141-3910(03)00028-4.

[19] K. Cao, Y. Ao, J. Chen, J. Peng, W. Huang, J. Li, M. Zhai, Gamma radiation effect of polymethylvinylphenylsiloxane rubbers under different temperatures, J. Appl. Polym. Sci. 134 (2017) 45404 https://doi.org/10.1002/app.45404.

[20] F. de Buyl, Silicone sealants and structural adhesives, Int. J. Adhesion Adhes. 21 (2001) 411-422 https://doi.org/10.1016/S0143-7496(01)00018-5.

[21] T.R.E. Simpson, B. Parbhoo, J.L. Keddie, The dependence of the rate of crosslinking in poly(dimethyl siloxane) on the thickness of coating, Polymer 44 (2003) 4829-4838 https://doi.org/10.1016/S0032-3861(03)00496-8.

[22] M.R. Ramli, M.B.H. Othman, A. Arifin, Z. Ahmad, Cross-link network of polydimethylsiloxane via addition and condensation (RTV) mechanisms. Part I: synthesis and thermal properties, Polym. Degrad. Stabil. 96 (2011) 2064-2070 https:// doi.org/10.1016/j.polymdegradstab.2011.10.001.

[23] P.H.J. Keizers, M.J. Vredenbregt, F. Bakker, D. de Kaste, B.J. Venhuis, Chemical fingerprinting of silicone-based breast implants, J. Pharmaceut. Biomed. 102 (2015) 340-345 https://doi.org/10.1016/j.jpba.2014.09.008.

[24] A.B. Birkefeld, R. Bertermann, H. Eckert, B. Pfleiderer, Liquid- and solid-state highresolution NMR methods for the investigation of aging processes of silicone breast implants, Biomaterials 24 (2003) 35-46 https://doi.org/10.1016/S0142-9612(02) 00241-7.

[25] B. Yactine, B. Boutevin, F. Ganachaud, Do-it-yourself functionalized silicones part 1 basic methods for characterization of commercial products, Polym. Adv. Technol. 20 (2009) 66-75 https://doi.org/10.1002/pat.1281.

[26] A. Formes, B. Diehl, Investigation of the silicone structure in breast implants using 1H NMR, J. Pharmaceut. Biomed. 93 (2014) 95-101 https://doi.org/10.1016/j. jpba.2013.09.005.

[27] A. Charlesby, R. Folland, J.H. Stephen, Analysis of crosslinked and entangled polymer networks as studied by nuclear magnetic resonance, Proc. Roy. Soc. Lond. A. 355 (1977) 189-207.

[28] R. Folland, A. Charlesby, Pulsed NMR studies of crosslinking and entanglements in high molecular weight linear polydimethylsiloxanes, Radiat. Phys. Chem. 10 (1977) 61-68 1977 https://doi.org/10.1016/0146-5724(77)90059-0.

[29] H. Menge, S. Hotopf, S. Poenitzsch, S. Richter, K.-F. Arndt, H. Schneider, U. Heuert, Investigation on the swelling behaviour in poly(dimethylsiloxane) rubber networks using nmr and compression measurements, Polymer 40 (1999) 5305-5313 https:// doi.org/10.1016/S0032-3861(98)00750-2.

[30] A.C.C. Esteves, J. Brokken-Zijp, J. Laven, H.P. Huinink, N.J.W. Reuvers, M.P. Van, G. de With, Influence of cross-linker concentration in the cross-linking of PDMS and the network structures formed, Polymer 50 (2009) 3955-3966 https://doi.org/10. 1016/j.polymer.2009.06.022.

[31] A.C.C. Esteves, J. Brokken-Zijp, J. Laven, H.P. Huinink, N.J.W. Reuvers, M.P. Van, G. de With, Garnet particles effect on the cross-linking of PDMS and the network structures formed, Polymer 51 (2010) 136-145 https://doi.org/10.1016/j.polymer. 2009.11.021.

[32] Q. Yuan, Y. Li, G. Li, Vulcanization kinetics of silicone rubber, Chin. J. Polym. Sci. 6 (1988) 353-358.

[33] S.J.F. Erich, J. Lavèn, L. Pel, H.P. Huinink, K. Kopinga, Dynamics of cross linking fronts in alkyd coatings, Appl. Phys. Lett. 86 (2005) 134105 https://doi.org/10. 1063/1.1886913.

[34] S.J.F. Erich, J. Lavèn, L. Pel, H.P. Huinink, K. Kopinga, NMR depth profiling of drying alkyd coatings with different catalysts, Prog. Org. Coating 55 (2006) 105-111 https://doi.org/10.1016/j.porgcoat.2005.08.009.

[35] R.M.E. Valckenborg, L. Pel, K. Hazrati, K. Kopinga, J. Marchand, Pore water distribution in mortar during drying as determined by NMR, Mater. Struct. 34 (2001) 599-604 https://doi.org/10.1007/BF02482126.

[36] L. Pel, P.A.J. Donkers, K. Kopinga, J.J. Noijen, ${ }^{1} \mathrm{H},{ }^{23} \mathrm{Na}$ and ${ }^{35} \mathrm{Cl}$ imaging in cementitious materials with NMR, Appl. Magn. Reson. 47 (2016) 265-276 https:/ doi.org/10.1007/s00723-015-0752-6.

[37] H.Y. Carr, E.M. Purcell, Effects of diffusion on free precession in nuclear magnetic resonance experiments, Phys. Rev. 94 (1954) 630-638 https://doi.org/10.1103/ PhysRev.94.630.

[38] S. Meiboom, D. Gill, Modified spin-echo method for measuring nuclear relaxation times, Rev. Sci. Instrum. 29 (1958) 688-691 https://doi.org/10.1063/1.1716296.

[39] K. Kopinga, L. Pel, One-dimensional scanning of moisture in porous materials with NMR, Rev. Sci. Instrum. 65 (1994) 3673-3681 https://doi.org/10.1063/1. 1144491

[40] A.K. Whittaker, The structure of polymer networks, in: G.A. Webb (Ed.), Modern Magnetic Resonance, Spriniger, Dordrecht, 2008, pp. 583-589 https://doi.org/10 1007/1-4020-3910-7 74.

[41] P.J. Flory, J. Rehner, Statistical mechanics of cross-linked polymer networks II. swelling, J. Chem. Phys. 11 (1943) 521-526 https://doi.org/10.1063/1.1723792.

[42] Y.-M. Sun, J. Chen, Sorption/desorption properties of ethanol, toluene, and xylene in poly(dimethylsiloxane) membranes, J. Appl. Polym. Sci. 51 (1994) 1797-1804 https://doi.org/10.1002/app.1994.070511014.

[43] A. Mahomed, D.W.L. Hukins, S.N. Kukureka, Swelling of medical grade silicones in liquids and calculation of their cross-link densities, Med. Eng. Phys. 32 (2010) 298-303 https://doi.org/10.1016/j.medengphy.2009.12.004.

[44] J.A. Barrie, B. Platt, The diffusion and clustering of water vapour in polymers, Polymer 4 (1963) 303-313 https://doi.org/10.1016/0032-3861(63)90038-7.

[45] E. Favre, P. Schaetzel, Q.T. Nguygen, R. Clément, J. Néel, Sorption, diffusion and vapor permeation of various penetrants through dense poly(dimethylsilocane) membranes: a transport analysis, J. Membr. Sci. 92 (1994) 169-184 https://doi. 
org/10.1016/0376-7388(94)00060-3.

[46] M.E. Rezac, T. John, P.H. Pfromm, Effect of copolymer composition on the solubility and diffusivity of water and methanol in a series of polyether amides, J. Appl. Polym. Sci. 65 (1997) 1983-1993 https://doi.org/10.1002/(SICI)10974628(19970906)65:10<1983::AID-APP16 > 3.0.CO;2-Y.

[47] S.J. Lue, S.Y. Wu, S.F. Wang, L.D. Wang, C.L. Tsai, Modeling multi-component vapor sorption in a poly(dimethyl siloxane) membrane, Desalination 233 (2008) 286-294 https://doi.org/10.1016/j.desal.2007.09.053.

[48] G. Steinbrecher, R. Scorei, V.M. Cimpoiasu, I. Petrisor, Stable reconstruction of the T2 distribution by low-resolution NMR measurements and the classical Markov and Hausdorf momentum problem, J. Magn. Reson. 146 (2000) 321-334 https://doi. org/10.1006/jmre.2000.2150.

[49] J.M. Watson, M.G. Baron, The behaviour of water in poly(dimethylsiloxane), J. Membr. Sci. 110 (1996) 47-57 https://doi.org/10.1016/0376-7388(95)00229-4.

[50] J.A. Barrie, D. Machin, The sorption and diffusion of water in silicone rubbers. Part I Unfilled rubbers, J. Macromol. Sci. B 3 (1969) 645-672 https://doi.org/10.1080/ 00222346908217112

[51] X. Wu, X. Li, L. Hao, X. Wen, L. Lan, X. Yuan, Q. Zhang, Effect of vulcanization temperature and humidity on the properties of RTV silicone rubber, IOP Conf. Ser. Mater. Sci. Eng. 207 (2017) 1-8 https://doi.org/10.1088/1757-899X/207/1/ 012011. 